\title{
Divergence of conditioned eyeblink and conditioned fear in backward Pavlovian training
}

\author{
KENNETH A. MCNISH, STEPHANIE L. BETTS, SUSAN E. BRANDON, and ALLAN R. WAGNER \\ Yale University, New Haven, Connecticut
}

\begin{abstract}
Two experiments of Pavlovian conditioning with rabbits evaluated the effects of initiating or continuing a conditioned stimulus (CS) after a paraorbital unconditioned stimulus (US). In Experiment 1 , backward pairings, in which a CS came on after the US, produced a CS that appeared inhibitory on a measure of eyeblink conditioning but excitatory on a potentiated-startle measure of conditioned fear. In Experiment 2, extending the duration of a CS that came on prior to the US, so that it continued after the US, decreased eyeblink conditioned responses, whereas it increased conditioned fear. The data from the two experiments confirm and extend those of Tait and Saladin (1986), supporting the suppositions of AESOP (Wagner \& Brandon, 1989) that conditioned eyeblink and conditioned fear can be dissociated under various temporal relationships between the CS and US.
\end{abstract}

Tait and Saladin (1986) reported that "backward" training, where an aversive unconditioned stimulus (US) was followed, rather than preceded, by a conditioned stimulus (CS), produced a CS that appeared concurrently excitatory and inhibitory, depending on the measure of associative learning employed. After 65 conditioning trials, where a $1,000-\mathrm{msec}$ tone CS was administered $500 \mathrm{msec}$ after a 100 -msec paraorbital shock US, the tone appeared excitatory as indicated by its acquired ability to suppress drinking behavior, whereas it appeared inhibitory as evidenced by its retardation in subsequent acquisition of eyeblink conditioned responses (CRs). Wagner and Brandon (1989) pointed to these data as providing especially clear evidence that CS-US pairings can produce an association between the CS and the emotive qualities of the US (as presumably reflected in common measures of conditioned fear) that is separable from the association between the $\mathrm{CS}$ and the remaining sensory-perceptual attributes of the US (as presumably seen in discrete CRs, such as the eyeblink). The separability is such that, under the conditioning parameters employed by Tait and Saladin, one association may be excitatory while the other is inhibitory.

The data reported by Tait and Saladin (1986) might have been anticipated on the basis of the separate literatures on fear conditioning and on eyeblink conditioning concerned with the effects of backward US-CS pairings. Studies of fear conditioning that have employed relatively short US-CS intervals have repeatedly reported an excitatory associative consequence (Ayres, Haddad, \& Albert, 1987; Burkhardt, 1980; Heth, 1976; Heth \& Rescorla,

The experiments were supported in part by National Science Foundation Grants BNS-8709680 and BNS-9121094 to A.R.W. Correspondence should be addressed to A. R. Wagner, P.O. Box 208205, New Haven, CT 06520-8205 (e-mail: wagner@yalevm.cis.yale.edu).
1973; Mahoney \& Ayres, 1976; Shurtleff \& Ayres, 1981; Singh, 1959; Williams, Dyck, \& Tait, 1986). In contrast, investigations of backward pairings in eyeblink conditioning have most frequently reported conditioned inhibition as the salient associative outcome (Hall, 1984; Plotkin \& Oakley, 1975; Siegel \& Domjan, 1971, 1974) and evidence of excitatory learning only under special experimental circumstances (Wagner \& Terry, 1975).

Nonetheless, there have been sufficient differences in the conduct of the separate studies of fear conditioning and eyeblink conditioning that one hardly could be confident that, under exactly the same conditions of backward training, a CS would appear excitatory on one measure but inhibitory on the other, as reported by Tait and Saladin (1986). Indeed, as pointed out by Williams, Dyck, and Tait (1986), one must question whether the difference in the two measures observed by Tait and Saladin might not have arisen from certain confoundings in their study. For instance, all subjects received the conditioned-suppression assessment, which involved a series of nonreinforced stimulus exposures, before the eyeblink conditioning assessment. Thus, it is possible that the backward training produced an excitatory tendency that was observed but extinguished during the first test, to leave an inhibitory tendency that was then detected in the second test. It also may be noted that the conditioned-suppression test was a simple, immediate-performance measure, whereas the eyeblink test involved a savings test over a course of subsequent training. It is possible that immediate-performance measures versus savings measures are differentially sensitive to excitatory tendencies versus inhibitory tendencies, regardless of the response involved.

The present experiments were designed to investigate further whether a CS can be concurrently excitatory with respect to one response system and inhibitory with respect to another, following backward Pavlovian training 
at a relatively short interstimulus interval. The two response systems investigated were presumed to be the same as those employed by Tait and Saladin (1986), although the eyeblink was measured from the outer eyelid rather than from the nictitating membrane, and conditioned fear was measured by the potentiation of the airpuffevoked startle response rather than lick suppression. The outer eyelid and the nictitating membrane are known to covary in conditioning (see, e.g., McCormick, Lavond, \& Thompson, 1982). The potentiated startle response to an airpuff stimulus in the rabbit has been shown in our laboratory (e.g., Brandon, Bombace, Falls, \& Wagner, 1991) to behave as a measure of the putative fear-eliciting properties of a $\mathrm{CS}$ in a manner akin to that observed via potentiated acoustic startle in the rat (Brown, Kalish, \& Farber, 1951; Davis, 1984, 1986).

Experiment 1 replicated the essential findings of Tait and Saladin (1986) in a design that avoided the aforementioned confoundings in their investigation. Experiment 2 supported and extended the results of Experiment 1 by demonstrating that adding a backward component to a forward CS (i.e., extending the CS duration beyond the occurrence of the US) caused the CS to show delayed acquisition of the conditioned eyeblink response but enhanced ability to potentiate the startle response.

\section{EXPERIMENT 1}

The purpose of Experiment 1 was to assess the effects of a backward-trained CS, in between-groups comparison with the baseline effects of an explicitly unpaired CS, on each of the two responses of interest, eyeblink CRs and startle URs. Both assessments made use of immediate performance tests involving presentations of the CS in conjunction, respectively, with a CS that had been trained to elicit an eyeblink CR or with an airpuff probe that elicited a startle UR. The order of assessment of the CS in regard to the two responses was equated by testing half the animals first on the eyeblink measure and second on the startle measure and by testing the remaining animals in the reverse order.

\section{Method}

Subjects. The subjects were 16 experimentally naive male New Zealand white rabbits, weighing between 1.5 and $2.5 \mathrm{~kg}$ at the start of training, divided into two groups of 8 . Each rabbit was individually housed and maintained with ad-libitum food and water, except during experimental sessions. The experiment was conducted in two replications, with 4 animals from each of the two groups in each replication. Two animals, 1 from each group in the second replication, were eliminated from the study due to illness immediately following the first test session; their data were excluded from all data descriptions and analyses.

Apparatus. Training and testing were conducted in eight identical $66 \times 48 \times 48 \mathrm{~cm}$ isolation chambers, allowing 8 animals to be run concurrently. Each chamber was completely lined with aluminum foil and illuminated by a $1-W$ neon bulb. Ventilation fans provided a constant background masking noise that raised the ambient sound pressure level to approximately $70 \mathrm{~dB}$ (re $20 \mu \mathrm{N} / \mathrm{m}^{2}$ ) in each chamber. During experimental sessions, each rabbit was loosely restrained within its chamber in a $51 \times 18 \times 14 \mathrm{~cm}$ Plexiglas box, from which its head protruded.

The apparatus provided for the administration of a light CS and a noise CS in relationship to a paraorbital shock US during training and to an airpuff probe during startle testing. The light CS was a 1,050-msec interrupted light ( 8 flashes/sec) generated by a strobe lamp located behind the subject so as to reflect diffusely from the walls of the chamber. The noise CS was a 2,000-msec broadspectrum noise that raised the sound pressure level to $90 \mathrm{~dB}$, presented through a $9.5-\mathrm{cm}$ loudspeaker also located behind the subject on the rear wall of the chamber. The US was a $50-\mathrm{msec}$ train of $100 / \mathrm{sec}, 4-\mathrm{mA}$ square-wave shock pulses produced by a constantcurrent generator and delivered through two \#32-ga stainless steel sutures implanted in the skin about the orbit of the subject's right eye. One suture was located approximately $5 \mathrm{~mm}$ ventral to the extreme nasal extent and the other approximately $5 \mathrm{~mm}$ caudal to the extreme lateral extent of the eye. The startle-producing stimulus was a 50 -msec, roughly square-waved pulse of air, measuring $5.51 \times 10^{4} \mathrm{~N} / \mathrm{m}^{2}$, delivered from a $1.0-\mathrm{mm}$ (ID) polyethylene tubing that was secured to the inner surface of the rabbit's pinna and directed to the auditory canal (see below). The air delivery was controlled by a solenoid valve and calibrated in duration and peak intensity by a Statham pressure transducer placed at the orifice of the delivery tubing proximal to the subject. All stimuli were under the control of Tektronix 160-series pulse generators and associated computer equipment.

Closure of the subject's eye was monitored via an adaptation of the photoresistive transducer described by Gormezano and Gibbs (1988). The transducer was taped directly to the animal's head and communicated with the lid by a length of thread tied to a small permanent recording suture loop. Movements of the eyelid turned a counterweighted wheel affixed to the axle of the transducer. The resulting signal was displayed on a polygraph, adjusted so that a 0.5 $\mathrm{mm}$ eyeliả closure produced a $1-\mathrm{mm}$ deflection of a recording pen.

The startle response to the airpuff was measured by means of an Astatic Model-16 phonocartridge taped to the subject's head. The cartridge held a metal rod, $1 \mathrm{~mm}$ in diameter and $50 \mathrm{~mm}$ in length, in place of a phonograph needle. When sudden movements of the subject's head caused the metal rod to oscillate, the cartridge produced a voltage proportional to the vigor of the movement. The voltage output from the movement transducer was graphically recorded on the same polygraph as the eyeblink, with a gain setting of $1 \mathrm{~V} / \mathrm{mm}$.

Preparation. On the day prior to training, each subject was habituated to confinement in the restraint boxes for $45 \mathrm{~min}$, during which time the dorsal surface of the head and the region surrounding the right eye were shaved, and the US electrodes and eyelid recording sutures were implanted.

Prior to startle testing, the auditory canal of the rabbit's left ear was cleared of wax and any debris, and the inner surface of the pinna was cleaned with ethanol to facilitate attachment of the air delivery tube. The tube was secured with vinyl tape so that it ran from the tip of the pinna, along the central artery, to end approximately $1 \mathrm{~cm}$ from the external auditory meatus. Effectiveness of the preparation was checked by ensuring that the rabbit would shake its head in response to a continuous stream of air delivered from a syringe through the attached tubing. 1

Training. Both groups of animals were trained with the light CS occurring in a forward arrangement with the US. The two groups differed in terms of their treatment with the noise CS. For Group Backward, the noise CS closely followed each US. For Group Unpaired, the noise CS also followed each US but at a grossly separated distance. The different temporal arrangements are depicted in the top panel of Figure 1. As indicated, the backward group received a training sequence in which the 1,050 -msec light CS overlapped and coterminated with the $50-\mathrm{msec}$ shock US, immediately followed by the 2,000 -msec noise CS. The unpaired group received the same forward pairing of the 1,050-msec light CS and the US but 
TRAINING CONDITIONS

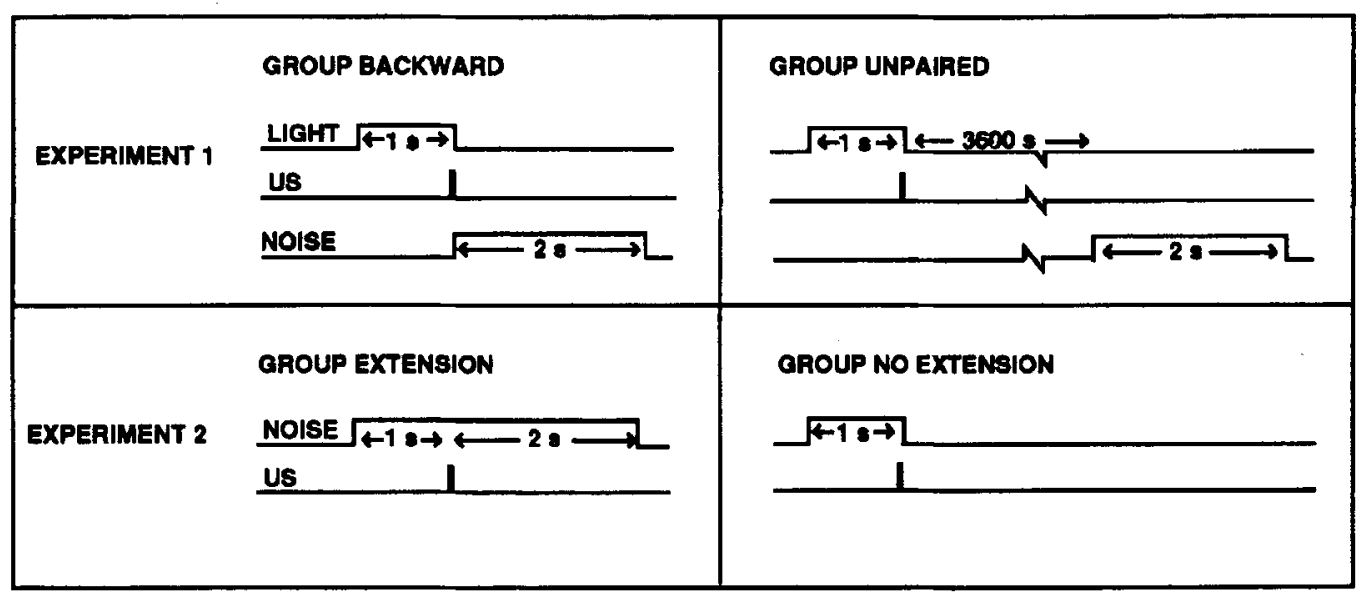

Figure 1. The top panels represent the temporal arrangement of CSs and US for Group Backward and Group Unpaired in Experiment 1. The US, which is indicated by the solid bar, was 50 msec in duration and coterminated with the light CS. The bottom panels represent the temporal arrangement of cues for Group Extension and Group No-Extension in Experiment 2. Here, again, the US, which is indicated by the solid bar, was 50 msec in duration and occurred 1,000 msec after the onset of the noise CS for both groups.

had a 6-min interval between US termination and the presentation of the 2,000-msec noise CS. The 1,000-msec interval employed between the onset of the light and the US in both groups was chosen because this interval has been shown to be effective for discriminative delay conditioning of the rabbit eyeblink CR (e.g., Wagner, 1969, 1976). The 2,000-msec duration of the noise CS was similarly chosen because backward durations spanning 2,000 msec have been shown to be effective for excitatory fear conditioning (e.g., Heth \& Rescorla, 1973; Mahoney \& Ayres, 1976). For both groups, the interval between successive US presentations was $12 \mathrm{~min}$.

The two groups received 10 sequences as described in the first training session and 20 additional in each of the next four sessions. Three subjects in each of the two groups who did not reach a criterion of $90 \%$ eyeblink CRs to the light CS in the fifth session were given an additional session of 20 trials. Training was completed with a final 10 trials on the day prior to testing for a total of 100 or 120 training trials.

The subjects in both groups were also given five separate sessions of exposure to the conditioning chambers without presentation of any CSs and USs. These sessions, which alternated with the training sessions in irregular order, were designed to minimize conditioned fear of the experimental context (Dweck \& Wagner, 1970). They were administered in the same manner as the training sessions, except that no stimuli were presented and they lasted only $45 \mathrm{~min}$.

Testing. All subjects were tested in separate sessions on two measures of associative learning to the noise CS, a measure of the influence of the CS upon the subjects' startle to the airpuff, and a measure of its influence on eyeblink CRs in combination with the light CS. In each test session, 12 total test trials were administered: 6 allowing measurement of the response to a probe stimulus (either the 50-msec airpuff or the 1,050-msec light CS) alone, and 6 allowing measurement of the response to the same probe stimulus in conjunction with the noise CS. When the influence of the noise $\mathrm{CS}$ was tested in conjunction with the airpuff, the puff was presented during the last $50 \mathrm{msec}$ of the $1,050-\mathrm{msec}$ stimulus. When the influence of the noise was tested in conjunction with the light $\mathrm{CS}$, the two were coextensive. None of the test trials in either session was reinforced with the paraorbital US.
Each test session began with five warm-up training trials, identical to the trials received by the subject on training days, followed by a single adaptation preexposure to the probe stimulus alone, prior to a balanced test order. The test trials with the probe stimulus alone or in conjunction with the noise CS were presented at 6min intertrial intervals in repeated $\mathrm{ABBA}$ or $\mathrm{BAAB}$ orders for different halves of each group.

Half of the subjects in each group were given the startle test involving the airpuff probe in the first session and the eyeblink test involving the light $\mathrm{CS}$ in the second session, whereas the remaining subjects were given the two tests in the reverse order. The two test sessions were separated by 2 days of retraining, consisting of 20 trials on the 1 st day and 10 trials on the 2 nd day, and two context extinction sessions.

Scoring and data analysis. An eyelid CR was scored to the light CS during training when the graphic record indicated an eyelid closure of $0.25 \mathrm{~mm}$ or more, initiated from 100 to $1,000 \mathrm{msec}$ after the onset of the CS. Because eyelid CRs to the noise CS during training would be expected to be obscured in the backward group by the preceding UR to the US and were observed to be virtually nonexistent in the unpaired group, they are ignored. Eyelid CR amplitude on light alone and light/noise trials during testing was defined as the maximum eyelid closure within the $1,200-\mathrm{msec}$ window that began $100 \mathrm{msec}$ after the onset of the CS.

Sudden movements of the subject's head produced by the airpuff during startle testing resulted in voltage changes that were graphically recorded as a rapidly damped, oscillating pattern of upward and downward pen deflections from a pre-CS baseline level. The amplitude of the startle response on puff alone and noise/puff trials was defined as the maximum peak-to-peak voltage recorded within the $300-\mathrm{msec}$ period beginning with the activation of the airpuff solenoid.

Response amplitudes were measured on both the eyelid and startle tests, rather than reporting response frequencies, because there were few test trials in which the probes did not produce a response. However, it should be noted that any trial in which a criterion response did not occur was scored as having a zero amplitude, producing aggregate measures of the form that Humphreys (1943) recommended calling response magnitude. 
Statistical analyses in this and the subsequent experiment employed analyses of variance (ANOVAs), followed by planned contrasts as warranted by a priori hypotheses. All differences said to be significant are associated with $p<.05$, two-tailed, except as noted.

\section{Results and Discussion}

During training, both the backward group and the unpaired group developed robust eyeblink CRs to the light CS that was commonly scheduled in forward relationship to the US. Every subject reached a $90 \% \mathrm{CR}$ criterion of responding to this CS by the end of training, with substantial mean CR amplitudes in the two groups. Over the last 20-trial block of training the mean CR amplitude to the light CS was $7.1 \mathrm{~mm}$ for Group Backward and $8.4 \mathrm{~mm}$ for Group Unpaired; these values were not reliably different $(t<1)$.

The data of primary interest are from the two test sessions that evaluated the eyeblink and startle-potentiating tendencies controlled by the noise CS that had been experienced either in a close backward relationship or relatively unpaired, with the US in the separate groups. Figure 2 summarizes the essential findings. The left panel shows the mean amplitude eyelid closure to the noiselight compound, as compared with the light CS alone, in each of the two groups. The right panel similarly shows the mean amplitude startle response to the noise-puff compound, as compared with the puff alone. In both graphs, the test performance of the backward group is shown on the left, and that of the unpaired group is shown on the right.

It should be noted in Figure 2 that the eyeblink responding to the light $\mathrm{CS}$ alone and startle to the airpuff alone were not markedly different in the two groups. In neither case did the group differences approach statistical reliability $[t<1$, and $t(10)=1.12$, respectively]. Analysis, therefore, could concentrate on the comparative increase or decrease from these levels that was observed in the re-

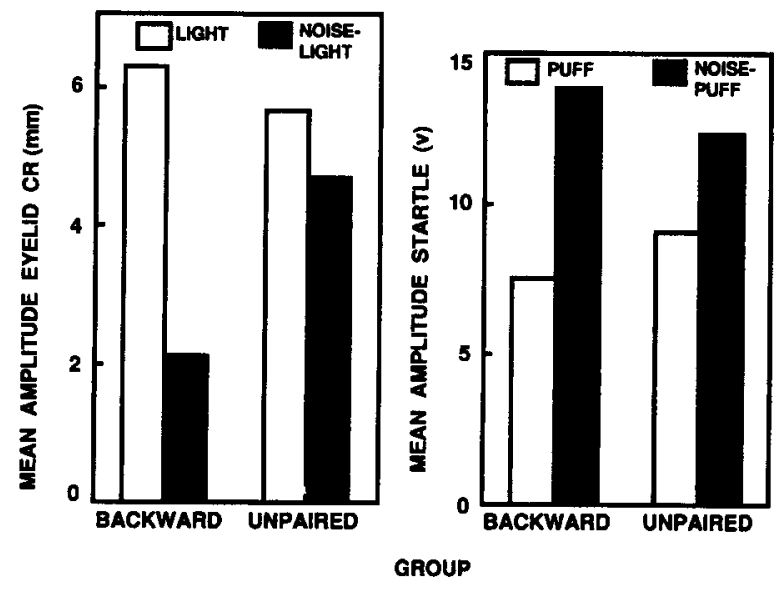

Figure 2. The left graph shows mean amplitude eyelid CRs to the light and the noise-light compound CSs in Group Backward and Group Unpaired. The right graph shows mean amplitude startle response to the puff and the noise-puff compounds in Group Backward and Group Unpaired in Experiment 1. sponding on test trials with the noise CS. On such evaluation, it may be seen that the unpaired group exhibited a small decremental effect of the noise CS on conditioned eyeblink and an equally small incremental effect on startle behavior. Although it is impossible from the available data to know if these influences reflected any associative consequences of the unpaired treatment, they are consistent in direction with previous observations in this laboratory on the unconditioned effects of auditory stimuli described by Brandon and Wagner (1991). In any event, the modest observed effects of the noise CS in the unpaired group was not statistically reliable in the case of eyeblink $(t<1.0)$ or startle $[t(12)=1.66]$.

In relationship to the baseline of influence of the noise CS on test responding in the unpaired group, it may be seen in Figure 2 that the noise CS in the backward group appeared to produce more of a decrement in eyeblink CRs and more of an increment in puff-elicited startle. An ANOVA performed on the differential responding to the probe stimuli in the presence versus absence of the noise CS by the two groups in the two test sessions revealed a significant groups $\times$ measure interaction $[F(1,12)=$ 5.60], confirming that backward, relative to unpaired, treatment produced differential effects on conditioned eyeblink versus potentiated startle. Subsequent contrasts indicated that the decrement in the conditioned eyeblink performance produced by the noise CS in the backward group was reliably greater than that in the unpaired group $[t(12)=2.73]$, whereas the increment in potentiated startle in the backward group was reliably greater than that in the unpaired group $[t(12)=1.99$, one-tailed].

The summary of test results in Figure 2 do not discriminate between the subgroups that received their two tests in the alternate orders. There was some tendency for the overall level of CR amplitude and the overall level of startle amplitude to be greater in the first session, relative to those in the second session, but there were no significant interactions of the experimental variables of concern with test order.

The results of Experiment 1 are in essential agreement with those of Tait and Saladin (1986). Backward US-CS training resulted in a CS that inhibited conditioned eyeblink more than did a CS that was experienced separate from the US. By usual reasoning, one would conclude that the backward CS had acquired an "inhibitory" associative tendency. At the same time, the backward training resulted in a CS that potentiated the startle response more than did a CS that was experienced separate from the US. By usual reasoning, one would conclude that the backward CS had acquired an "excitatory" associative tendency. Thus, the same backward-trained CS appeared simultaneously inhibitory on a measure of conditioned eyeblink and excitatory on a measure of conditioned fear.

The different outcomes with the two measures canno: be attributed to gross differences in the form of testing in the two cases, insomuch as both were assessed using very similar "summation" procedures. Even more clearly, the different outcomes cannot be attributed to differences in the order of testing in the two cases, since this variable 
was carefully counterbalanced and found not to be influential. The worrisome confoundings of the Tait and Saladin study do not appear to be critical to the reported findings that were replicated in Experiment 1.

One can raise other interpretive challenges, however. There are, for example, a number of possibilities for differential associative effects in Group Backward versus Group Unpaired, in addition to the differential backward associations between the tone and the US, and some of these could, conceivably, have differential impact upon the two test measures. Thus, in Group Backward, the tone was in better temporal position during training potentially to develop backward associations with the light, as well as with the US, and to interfere with the associative loadings that would normally accrue between the light and the US (see, e.g., Mazur \& Wagner, 1982). There was, in fact, no indication of the latter, interference effect: As reported above, the two groups did not differ in the amplitude of conditioned responding observed to the light alone, in either training or testing. It is not clear what specific influence would be expected on the basis of any differential direct associations between the tone and the light. However, one might be concerned that tone-light associations could have an influence on tests of the effectiveness of the tone when it was presented in conjunction with the light (as in the eyeblink summation tests of Experiment 1) that they would not have on tests in the absence of the light (as in the startle tests of Experiment 1). The design of Experiment 2 avoided any such differential influence by avoiding the use of the light CS in training and testing. It also avoided another relatively uninteresting interpretation that could be given to the results of Experiment 1 , as will be indicated.

\section{EXPERIMENT 2}

Experiment 2 was designed as a further investigation of the backward-training arrangement of US followed by CS, under which conditioned eyeblink and conditioned fear might be dissociated. It focused on the effects of continuing, beyond the time of US occurrence, a CS that had come on before the US.

Previous studies that have investigated the effects of continuing a CS beyond the time of US occurrence, as compared with the more conventional practice of terminating the CS contemporaneous with US presentation, frequently have reported a decrement in the conditioning of either discrete conditioned reflexes (e.g., Barnes, 1956; Schneiderman, 1966) or CERs (e.g., Ayres \& Albert, 1990; Ayres, Albert, \& Bombace, 1987; Larew, 1986). ${ }^{2}$ However, the studies concerned with discrete CRs have employed post-US durations quite different from those concerned with presumptive measures of conditioned fear. Schneiderman (1966) reported a decremental effect on eyeblink conditioning in the rabbit of continuing the CS 2 sec beyond the US. Likewise, Barnes (1956) reported decreasing levels of leg flexion conditioning in dogs as the post-US CS was increased from 0 to 5,15 , and $30 \mathrm{sec}$.
In contrast, the decremental effects on conditioned fear in the rat reported by Ayres and Albert (1990) and Ayres, Albert, and Bombace (1987) resulted from a 10-min extension of the CS. Notably, Larew (1986), in separate experiments, observed a decremental effect on conditioned fear of a 60 -sec extension of the CS, but not of a $30-\mathrm{sec}$ extension. There have been no studies of the effects of CS extension that have looked at both classes of responses under the same conditions.

Experiment 2 evaluated the effects on conditioned eyeblink and conditioned potentiation of the startle response of extending a "forward" CS 2-sec post-US, as compared with coterminating the CS with the US, during training. Given the contrasting inhibitory versus excitatory effects observed on the two response measures in Experiment 1 as a result of initiating a 2 -sec CS immediately after the US, it appeared possible that the 2 -sec post-US extension, while having a decremental (inhibitory) effect on conditioned eyeblink as reported by Schneiderman (1966), would have an incremental (excitatory) effect on startle potentiation.

In Experiment 1, the condition against which the "backward" treatment was evaluated was one that involved the same exposure to the CS, but at a long (6-min) distance from the preceding US, calculated to preclude direct CSUS association. In this comparison, one might be concerned that some or all of the differences in responding to the CS was a result not of greater associative learning to the CS in the backward group (relative to the unpaired group) but, rather, of less habituation to the CS. The possibility that a contemporaneous US can interfere with the habituation of unconditioned tendencies to a CS is often difficult to distinguish from the associative effects of stimulus pairing (see, e.g., Pfautz, Donegan, \& Wagner, 1978; Sharp, James, \& Wagner, 1980).

It is, thus, of interpretive significance that, in Experiment 2 , the condition against which the backward CSextension treatment was evaluated was one with no postUS CS exposure (i.e., one that should have provided less, rather than more, opportunity for CS habituation). If the greater inhibition of eyeblink behavior and/or the greater facilitation of startle in the backward condition, relative to that in the control condition, of Experiment 1 were due to less CS habituation, one would expect to see that difference reversed in the corresponding comparison of Experiment 2. One would not, according to a variablehabituation account, expect to see diminished eyeblink and facilitated startle in the CS-extension treatment, relative to the no-extension condition, of Experiment 2.

\section{Method}

Subjects. The subjects were 14 experimentally naive male New Zealand white rabbits maintained and prepared as those in Experiment 1 . They were assigned to two experimental groups of 7 subjects and to two running squads each composed of equal proportions of subjects from the two groups.

Apparatus. The apparatus was the same as that used in Experiment 1 . The $90-\mathrm{dB}$ noise that functioned as the backward or unpaired CS in Experiment 1 was employed as the only CS. 
Training. For all subjects, each training trial began with a CS that preceded by $1,000-\mathrm{msec}$ a 50 -msec paraorbital shock US. For Group No-Extension, the CS and US terminated together. For Group Extension, the CS continued for an additional 2,000 $\mathrm{msec}$ beyond the US. The different arrangements are depicted in the lower panel of Figure 1. As indicated, the only difference between the two treatments was the backward CS component, beyond the time of the US, given to Group Extension.

Initial training was accomplished in 60 conditioning trials distributed over two sessions, 20 trials in the first session and 40 in the second. The interval between successive US presentations within each session was uniformly $4 \mathrm{~min}$.

Startle testing. The potentiating effects of the noise CS on the airpuff-elicited startle response in the two groups were evaluated in a single test session administered on the following day. The session began with five warm-up conditioning trials, identical to those received on the training days. Sixteen test trials followed, involving 8 presentations of the $50-\mathrm{msec}$ puff alone and 8 presentations in which the puff was preceded by the 1,050 -msec noise $\mathrm{CS}$, as in Experiment 1 . The sequence of the two kinds of test trials was such as to balance the first order sequential probabilities, beginning with the airpuff alone for half of the subjects in each group and with the airpuff in the presence of the noise CS for the remainder. The intertrial interval during testing was $4 \mathrm{~min}$.

Eyeblink retesting. In order to determine whether any difference in group relationships on the eyeblink and the startle measures was independent of the order of assessment, on the day following startle testing, all animals were given an additional conditioning session, identical to that which preceded the startle testing, in which eyeblink CRs could again be evaluated.

Scoring. The frequency and amplitude of eyeblink conditioned responses during the training sessions and the amplitude of the startle responses in the test session were scored using the same procedures as in Experiment 1.

\section{Results and Discussion}

Figure 3 depicts the course of eyeblink CR acquisition to the noise CS over blocks of 10 training trials for the two groups. As may be seen, continuing the CS for $2 \mathrm{sec}$ beyond the US appeared to provide a small initial advantage, followed by a more substantial and persistent decrement, in conditioning for the extension group relative to that for the no-extension group. A repeated measures ANOVA of the frequency of CRs in the two groups revealed a reliable group $\times$ training block interaction $[F(5,60)=2.60]$. Subsequent analyses of the differences in response frequency between the two groups at the different stages of training indicated no reliable differences in eyeblink performance until the last three blocks of training, over which course the eyeblink performance of the extension group was reliably impaired relative to that of the no-extension group $[t(13)=7.81]$.

Amplitude of response data from the last day of eyeblink training and the following startle test day are shown together in Figure 4. The left panel depicts the mean amplitude eyelid closure to the CS for the extension group on the left and for the no-extension group on the right. It is evident that CR amplitude was suppressed, as was CR frequency (see Figure 2), for that group in which the CS extended beyond the US relative to that for the group in which the CS terminated with the US.

There was no reliable difference between the groups in the mean startle to the puff alone $[t(12)=1.14]$. However,

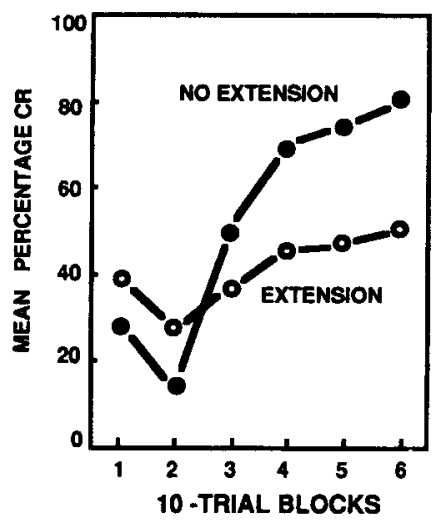

Figure 3. Mean percentage CRs to the light CS across 10-trial blocks of acquisition training for Group No-Extension and Group Extension in Experiment 2.

there was a substantial difference in the startle-potentiating effects of the CS. The right panel in Figure 4 shows this effect, calculated as the mean difference in startle amplitude to the puff in those tests with the CS versus those with the puff alone, again for the extension group on the left and the no-extension group on the right. A pattern opposite to that seen in the eyeblink data is evident here: In the startle assessment, that group in which the CS extended beyond the US showed greater potentiated startle than did the group in which the CS terminated with the US.

Statistical analyses supported these conclusions. A repeated measures ANOVA showed a reliable interaction of group $\times$ measure $[F(1,12)=6.69]$. Subsequent planned contrasts showed that the amplitude of eyeblink CRs to the CS was significantly less in the extension group than in the no-extension group $[t(12)=2.20]$, but that the reverse was true for the startle measure: The amplitude of startle potentiation by the CS was significantly greater in the extension group than in the no-extension group $[t(12)=2.25]$

Analyses of CR eyeblink frequency in the poststartletesting session showed that the same difference in CR frequency that had obtained between the two groups prior to startle testing also obtained after startle testing. The mean frequency of eyeblink CRs in the first block of 10 trials was 85.7 for the no-extension group and 54.3 for the extension group, and this difference was statistically reliable $[t(12)=5.87]$. The consistency of the difference in eyeblink CR frequency between the two groups before and after the startle test discourages any interpretation of the contrasting results on the startle measures versus the eyeblink measures in terms of some opportunity for change in the associative strength of the CS between the two measurement occasions.

The experience provided the two groups in Experiment 2 differed only in the extension of the CS beyond the termination of the US in one case and not in the other. The different relative eyeblink and startle performances of the two groups can, thus, be attributed to this extension, or backward component, of the CS. The backward CS ex- 

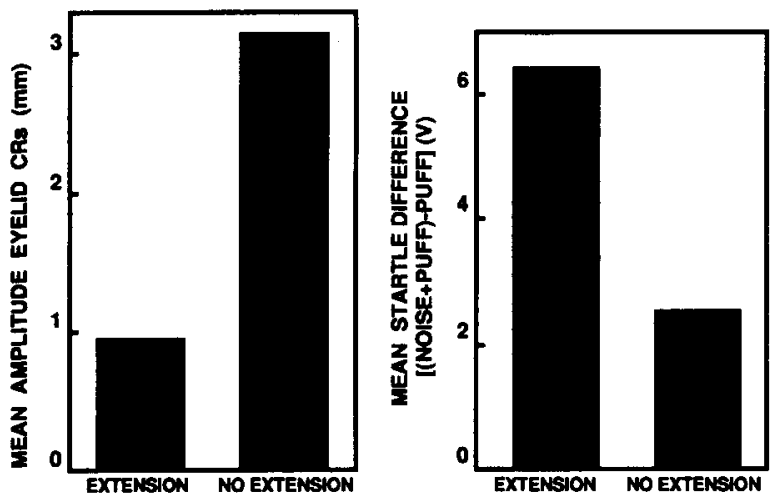

GROUP

Figure 4. For Experiment 2, the left graph shows mean amplitude eyelid CRs to the noise CS on the last day of training, and the right graph shows the mean startle difference I(puff + noise) - puff] in the subsequent test session. The left and right panels in each graph are for Groups Extension and No-Extension, respectively.

tension impaired performance of the conditioned eyeblink response but increased the potentiation of the startle response controlled by that $\mathrm{CS}$. The pattern implies that the backward CS extension acted contrary (i.e., inhibitory) to the otherwise excitatory associative tendencies reflected in the conditioned eyeblink, at the same time that it acted excitatory to the associative tendencies reflected in the potentiated startle.

The pattern of findings in Experiment 2 would not be expected from the differential-habituation interpretation that could be entertained in regard to the results of Experiment 1 . Greater CS habituation might have resulted from the added CS exposure given to the extension group. Such an effect might have reduced the acquisition of eyeblink responding, as observed. However, greater CS habituation should, then, also have reduced the acquisition of the potentiated-startle response. In Experiment 2, just as in Experiment 1 and the prior study by Tait and Saladin (1986), post-US CS exposure had the opposite effect on conditioned fear than it had on conditioned eyeblink.

\section{GENERAL DISCUSSION}

The data of Experiments 1 and 2 increase our confidence that the phenomenon reported by Tait and Saladin (1986) represents a reproducible dissociation of measures of eyeblink conditioning and measures of conditioned fear. Vandercar and Schneiderman (1967) made the point some years ago that variation in the interval by which the CS precedes the US has notably different effects upon simultaneously recorded measures of nictitating membrane conditioning and heart rate conditioning. It appears that a "divergence of response systems," as they called it, is even more obvious when backward US-CS intervals are surveyed. With a short backward interval, as employed by Tait and Saladin and used in the present experiments, the consequences of stimulus pairing can have different valences for the two measures, being inhibitory for eyeblink conditioning and being excitatory for a measure of conditioned fear.

Pavlov (1927) established a strategy, which has frequently been employed in subsequent theories (e.g., Hull, 1943; Konorski, 1948; Rescorla, 1985; Spence, 1936; Wagner, 1981), of treating conditioned responding as being the net result of opposing excitatory and inhibitory influences that accrue during training. He argued that excitation and inhibition have important differences (e.g., that excitation is associative in origin and relatively impervious to decremental influences, whereas inhibition is nonassociative and relatively labile, decreasing more with the passage of time and extraneous stimulation). The reasoning that a manipulation might, therefore, decrement inhibition more than excitation allowed Pavlov (1927) to account for instances of "spontaneous recovery" resulting from a rest interval and "external disinhibition" resulting from extraneous stimulation.

Given this precedent, one's first response in interpreting an apparent difference in the excitatory/inhibitory balance observed in two different measures of performance would be to ask whether the separate measures were recorded under circumstances that might have differentially favored the integrity of the two tendencies. In this vein, we questioned whether the order of testing employed by Tait and Saladin (1986), starting with the measurement of conditioned fear over a series of nonreinforced trials and only subsequently measuring the eyeblink, might not have been critical to the former appearing excitatory but the latter inhibitory. The possibility appeared more plausible in light of the finding of Williams and Overmier (1988; see also Williams, Travis, \& Overmier, 1986) that CSs trained to be inhibitory under several different procedures, including backward conditioning, were more demonstrably so after a series of nonreinforced extinction trials. The authors reasoned that the extinction trials reduced collateral excitation, which otherwise masked the inhibition that had developed. The results of Experiment 1, in which the order of testing of the eyeblink and conditioned fear were carefully balanced, allow us to reject the sufficiency of this particular interpretation of the Tait and Saladin phenomenon.

Although an attempt was made in the present experiments to avoid other unnecessary differences in the conditions under which the two response measures were recorded, we could not eliminate all differences of potential interpretive significance. Thus, for example, the measure of conditioned fear involved the application of a novel, startle-producing pulse of air, whereas the measure of conditioned eyeblink, instead, involved either the joint application of another CS (Experiment 1) or no other stimulation (Experiment 2). Thus, it is conceivable that the air pulse may have acted not only to evoke a startle response, as measured, but as an especially effective external disinhibitor, thereby making contemporaneous measures of 
the associative loadings of the CS appear more singularly excitatory than they did on the occasions of the eyeblink measure. We can only point out that the empirical and theoretical underpinnings for such an argument are less than secure. On one hand, Bouton (1993) has summarized a recent literature on shifts in context as indicating, à la Pavlov, that inhibition may, indeed, be more sensitive than excitation to changes in physical (and temporal) context. On the other hand, the modern Pavlovian literature on external disinhibition from punctate stimuli has found the phenomenon to be "elusive" (Marchant, 1975) and not a robust source of influence (Gormezano, 1958). It is interesting that theorists who have followed Pavlov in adopting an antagonistic-processes view of conditioning have generally differed from Pavlov in treating both excitation and inhibition as being associative in origin (see Hawkins $\&$ Kandel, 1984, for an exception) without providing a rationalization for why one might, then, be more disrupted by extraneous stimulation than the other.

There is more encouragement to suppose that the differences in the results observed with the eyeblink and startle measures are tied to the different conditioned responses and the different associative structures that they reflect. Considerable data now document the separability of conditioned eyeblink and conditioned fear during Pavlovian conditioning with an aversive paraorbital US. In addition to the aforementioned behavioral observations of Vandercar and Schneiderman (1967; see also Brandon, Betts, \& Wagner, 1994, and Brandon \& Wagner, 1991) showing differential variation as a function of the CS-US interval, there is substantial literature attesting to the differential speed of acquisition of the two measures (see review by Lennartz \& Weinberger, 1992; but see also Kehoe \& Macrae, 1994, and Lennartz \& Weinberger, 1994), and the report of Betts, Brandon, and Wagner (1996) showing that shift of the US from one eye to the other spares blocking of conditioned fear but not blocking of conditioned eyeblink. These behavioral observations are supported by neurobiological investigations that suggest that the locus of neural convergence essential for eyeblink conditioning is different from that for fear conditioning (e.g., Thompson, 1986): Instructive is the fact that cerebellar damage that prevents eyeblink conditioning does not prevent fear conditioning (Thompson et al., 1986), whereas amygdala lesions that interfere with fear conditioning do not preclude eyeblink conditioning (e.g., Weisz, Harden, \& Xiang, 1992). The body of evidence, including the differential effects of backward conditioning reported by Tait and Saladin (1986) and confirmed in Experiments 1 and 2, is consistent with those treatments of Pavlovian conditioning (e.g., Konorski, 1967; Wagner \& Brandon, 1989; Weinberger, 1982) that suppose that different associations underlie specific conditioned reflexes, such as the eyeblink, versus more generally influential conditioned emotional responses, such as conditioned fear, which may be concurrently acquired.
The question remains, if there is a dissociation of conditioned eyeblink and conditioned fear under conditions of backward CS-US pairings, why is it the case that the eyeblink association is inhibitory whereas that for conditioned fear is excitatory, rather than, say, the reverse? An answer to this question requires some suppositions about the characteristic determinants of excitatory and inhibitory associative learning under the possible temporal relationships of CS and US and how these might be assumed to differ for conditioned eyeblink and conditioned fear. Wagner and Brandon (1989) offered one interpretation by way of an extension of the real-time model, SOP, developed by Wagner and colleagues (Donegan \& Wagner, 1987; Mazur \& Wagner, 1982; Pfautz, 1980; Wagner, 1981; Wagner \& Donegan, 1989).

A basic assumption of SOP is that associative learning occurs when CS processing temporally overlaps either of two stages of US processing: a primary stage of representational activity, A1, which supports excitatory learning, and a secondary stage, $\mathrm{A} 2$, which supports inhibitory learning. According to this model, presenting a CS before, rather than after, a US is generally more effective in producing net excitatory learning, because CS processing will, then, preferentially overlap the initial activity, A1, rather than the subsequent activity, A2, produced by the US. Presenting a CS after, rather than before, a US at a short interval may still produce net excitatory learning for the same reason, but, with greater "backward" asynchrony, the more general outcome should be to produce net inhibitory learning, because CS processing will, then, preferentially overlap the secondary activity, $\mathrm{A} 2$, rather than the primary activity, A1, produced by the US (see Mazur \& Wagner, 1982, pp. 15-20, for quantitative simulations).

Wagner and Brandon (1989) proposed that the emotional attributes of the US that support the conditioning of fear have $A 1$ and $A 2$ processes that are independent of those of the remaining sensory-perceptual attributes of the US responsible for conditioned eyeblink. To explain the results of Tait and Saladin (1986), they proposed that the two stages of emotional processing initiated by a US are more protracted than are those of the sensoryperceptual processing initiated by the same US. Thus, under conditions where the CS shortly follows the US, CS processing might preferentially overlap the $\mathrm{Al}$, as compared with the $\mathrm{A} 2$, activity responsible for conditioned fear, so that the CS would become associatively excitatory on this measure, but, nonetheless, preferentially overlap the $\mathrm{A} 2$, rather than the $\mathrm{A} 1$, activity responsible for conditioned eyeblink, so that the CS would be associatively inhibitory on this measure (see Wagner \& Brandon, 1989, pp. 171-174, for quantitative simulations of the assumed theoretical processes). The same reasoning would apply to the results of Experiment 1 . It can be extended to the related results of Experiment 2, with the understanding that the excitatory versus inhibitory consequences of added post-US processing of the CS for the two measures either adds to or detracts from the excita- 
tory learning otherwise produced by the forward CS-US relationship.

The key assumption - that the $\mathrm{A} 1$ and $\mathrm{A} 2$ processing of the emotional attributes of a US is more protracted than that of the remaining sensory-perceptual attributes of the US-is consistent with the aforementioned facts that conditioned fear is acquired faster and at longer CS-US intervals than is conditioned eyeblink. It also leads to the prediction that, under circumstances of backward conditioning, the particular pattern of fear conditioning being excitatory and eyeblink conditioning being inhibitory, observed by Tait and Saladin (1986) and in the present studies, is peculiar to the relatively short US-CS interval employed. For example, with longer US-CS intervals, the consequences would be expected to become inhibitory, rather than excitatory, for fear conditioning (as Larew, 1986, observed them to be at $60 \mathrm{sec}$ ) but, then, to be beyond the point of being inhibitory (i.e., to be neutral) for eyeblink conditioning. With still longer US-CS intervals, the associative implications for both behaviors should be neutral. The predictions concerning these temporal variations have not been tested.

The interpretation offered by Wagner and Brandon (1989) falls within a major tradition of "two-process" theory (e.g., Konorski, 1967; Miller, 1963; Mowrer, 1960; Schlosberg, 1937; Spence, 1956), which supposes, in one form or another, a fundamental distinction between the antecedents and functional consequences of conditioned emotional responses versus specific acquired reflexes. It remains to be seen whether the distinction emphasized in this manner of theory will account for a theoretically significant portion of the variance in the excitatory and inhibitory learning that may be observed in studies of backward conditioning, using responses other than a measure of conditioned fear and a measure of conditioned eyeblink, as presently employed.

\section{REFERENCES}

Ayres, J. J. B., \& Albert, M. (1990). Extending conditioned stimuli before vs after unconditioned stimuli: Convergence of effect over trials. Learning \& Motivation, 21, 399-414.

Ayres, J. J. B., Albert, M., \& Bombace, J. C. (1987). Extending conditioned stimuli before versus after unconditioned stimuli: Implications for real-time models of conditioning. Journal of Experimental Psychology: Animal Behavior Processes, 13, 168-181.

AYres, J. J. B., HADDAD, C., \& AlberT, M. (1987). One-trial excitatory backward conditioning as assessed by conditioned suppression of licking in rats: Concurrent observations of lick suppression and defensive behaviors. Animal Learning \& Behavior, 15, 212-217.

Barnes, G. W. (1956). Conditioned stimulus intensity and temporal factors in spaced trial classical conditioning. Journal of Experimental Psychology, 51, 192-198.

BeTtS, S. L., Brandon, S. E., \& WAGNER, A. R. (1996). Dissociation of the blocking of conditioned eyeblink and conditioned fear following a shift in US locus. Animal Learning \& Behavior, 24, 459-470.

Bouton, M. E. (1993). Context, time, and memory retrieval in the interference paradigms of Pavlovian learning. Psychological Bulletin, 114, 80-99.

Brandon, S. E., Betts, S. L., \& Wagner, A. R. (1994). Discriminated, lateralized, eyeblink conditioning in the rabbit: An experimental context for separating specific and general associative influences. Journal of Experimental Psychology: Animal Behavior Processes, 20, 292-307.
Brandon, S. E., Bombace, J. C., Falls, W. T., \& Wagner, A. R. (1991). Modulation of unconditioned defensive reflexes via an emotive Pavlovian conditioned stimulus. Journal of Experimental Psychology: Animal Behavior Processes, 17, 312-322.

Brandon, S. E., \& WaGNER, A. R. (1991). Modulation of a discrete Pavlovian conditioned reflex by a putative emotive Pavlovian conditioned stimulus. Journal of Experimental Psychology: Animal Behavior Processes, 17, 299-311.

Brown, J. S., Kalish, H., \& FARBER, I. E. (1951). Conditioned fear as revealed by magnitude of startle response to an auditory stimulus. Journal of Experimental Psychology, 41, 317-328.

BURKHARDT, P. E. (1980). One-trial backward fear conditioning as a function of US intensity. Bulletin of the Psychonomic Society, 15, 9-11.

DavIs, M. (1984). The mammalian startle response. In R. C. Eaton (Ed.), Neural mechanisms of startle behavior (pp. 287-351). New York: Plenum.

DAvis, M. (1986). Pharmacological and anatomical analysis of fear conditioning using the potentiated startle paradigm. Behavioral Neuroscience, 100, 808-818.

Donegan, N. H., \& Wagner, A. R. (1987). Conditioned diminution and facilitation of the UR: A sometimes-opponent-process interpretation. In I. Gormezano, W. F. Prokasy, \& R. F. Thompson (Eds.), Classical conditioning III (pp. 339-369). Hillsdale, NJ: Erlbaum.

DWECK, C. S., \& WAGNER, A. R. (1970). Situational cues and correlation between CS and US as determinant of the conditioned emotional response. Psychonomic Science, 18, 145-147.

FALLS, W. A., \& WAGNER, A. R. (1991). Airpuff-elicited startle in the rabbit (Oryctolagus cuniculus). Unpublished manuscript.

GoRMEZANo, I. (1958). An investigation of disinhibition and its effect on spontaneous recovery in classical eyelid conditioning. Unpublished doctoral dissertation, University of Wisconsin, Madison.

Gormezano, I., \& GibBs, C. M. (1988). Transduction of the rabbit's nictitating membrane response. Behavior Research Methods, Instruments, \& Computers, 20, 18-21.

HALL, J. F. (1984). Backward conditioning in Pavlovian type studies: Reevaluation and present status. Pavlovian Journal of Biological Science, 19, 163-168.

HAWKINS, R. D., \& KANDEL, E. R. (1984). Is there a cell-biological alphabet for simple forms of learning? Psychological Review, 91, 375-391

HETH, C. D. (1976). Simultaneous and backward fear conditioning as a function of the number of CS-UCS pairings. Journal of Experimental Psychology: Animal Behavior Processes, 2, 117-129.

HETH, C. D., \& RESCORLA, R. A. (1973). Simultaneous and backward fear conditioning in the rat. Journal of Comparative \& Physiological Psychology, 82, 434-443.

Hull, C. L. (1943). Principles of behavior. New York: AppletonCentury-Crofts.

HUMPHREYS, L. G. (1943). Measures of strength of conditioned eyelid responses. Journal of General Psychology, 29, 101-111.

KehoE, E. J., \& MACrae, M. (1994). Classical conditioning of the rabbit nictitating membrane response can be fast or slow: Implications for Lennartz and Weinberger's (1992) two-factor theory. Psychobiology, 22, 1-4.

KONORSKI, J. (1948). Conditioned reflexes and neuron organization. Cambridge: Cambridge University Press.

Konorski, J. (1967). Integrative activity of the brain. Chicago: University of Chicago Press.

LAREW, M. B. (1986). Inhibitory learning in Pavlovian backward conditioning procedures involving a small number of US-CS trials. Unpublished doctoral dissertation, Yale University.

LenNartz, R. C., \& WeInBerger, N. M. (1992). Analysis of response systems in Pavlovian conditioning reveals rapidly versus slowly acquired conditioned responses: Support for two factors, implications for behavior and neurobiology. Psychobiology, 20, 93-119.

LENNARTZ, R. C., \& WeINBERGER, N. M. (1994). A comparison of nonspecific and nictitating membrane conditioned responses: Additional support for two-factor theories. Psychobiology, 22, 5-15.

MAHONEY, W. J., \& AYRES, J. J. B. (1976). One-trial simultaneous and backward fear conditioning as reflected in conditioned suppression of licking in rats. Animal Learning \& Behavior, 4, 357-362.

MARCHANT, H. G., III (1975). Disinhibition of the rabbit's conditioned 
nictitating membrane response. Unpublished doctoral dissertation, University of Massachusetts, Amherst.

MazUR, J. E., \& WaGner, A. R. (1982). An episodic model of associative learning. In M. Commons, R. Herrnstein, \& A. R. Wagner (Eds.), Quantitative analyses of behavior: Acquisition (Vol. 3, pp. 339). Cambridge, MA: Ballinger.

McCormick, D. A., Lavond, D. G., \& Thompson, R. F. (1982). Concomitant classical conditioning of the rabbit nictitating membrane and eyelid responses: Correlations and implications. Physiology \& Behavior, 28, 769-775.

MiLleR, N. E. (1963). Some reflections on the law of effect produce a new alternative to drive reduction. In M. R. Jones (Ed.), Nebraska symposium on motivation (Vol. 11, pp. 65-112). Lincoln: University of Nebraska Press.

MOWRER, O. H. (1960). Learning theory and behavior. New York: Wiley.

PavLov, I. P. (1927). Conditioned reflexes (G. V. Anrep, Trans.). London: Oxford University Press.

PFAUTZ, P. L. (1980). Unconditioned facilitation and diminution of the unconditioned response. Unpublished doctoral dissertation, Yale University.

Pfautz, P. L., Donegan, N. H., \& Wagner, A. R. (1978). Sensory preconditioning versus protection from habituation. Journal of Experimental Psychology: Animal Behavior Processes, 4, 286-295.

PlotKIN, R. C., \& OAKLEY, P. A. (1975). Backward conditioning in the rabbit (Oryctolagus cuniculus). Journal of Comparative \& Physiological Psychology, 88, 586-590.

RESCORLA, R. A. (1985). Inhibition and facilitation. In R. R. Miller \& N. E. Spear (Eds.), Information processing in animals: Conditioned inhibition (pp. 299-326). Hillsdale, NJ: Erlbaum.

SCHLOSBERG, H. (1937). The relationship between success and the laws of conditioning. Psychological Review, 44, 379-394.

SCHNEIDERMAN, N. (1966). Interstimulus interval function of the nictitating membrane response of the rabbit under delay versus trace conditioning. Journal of Comparative \& Physiological Psychology, 62, 397-402

SharP, P. A., JAMES, J. H., \& WAGNer, A. R. (1980). Habituation of a "blocked" stimulus during Pavlovian conditioning. Bulletin of the Psychonomic Society, 15, 139-142.

ShuRTLEFF, D., \& AYRES, J. J. B. (1981). One-trial backward excitatory fear conditioning in rats: Acquisition, retention, extinction, and spontaneous recovery. Animal Learning \& Behavior, 9, 65-74.

Siegel, S., \& DomjaN, M. (1971). Backward conditioning as an inhibitory procedure. Learning \& Motivation, 2, 1-11.

SiEgel, S., \& Domian, M. (1974). The inhibitory effect of backward conditioning as a function of the number of backward pairings. $B u l$ letin of the Psychonomic Society, 4, 122-124.

SINGH, S. D. (1959). Conditioned emotional response in the rat: I Constitutional and situational determinants. Journal of Comparative \& Physiological Psychology, 52, 574-578.

SPENCE, K. (1936). The nature of discrimination learning in animals. Psychological Review, 43, 427-449.

SPENCE, K. (1956). Behavior theory and conditioning. New Haven, CT: Yale University Press.

TAIT, R. W., \& Saladin, M. E. (1986). Concurrent development of excitatory and inhibitory associations during backward conditioning. Animal Learning \& Behavior, 14, 133-137.

Thомpson, R. F. (1986, August 29). The neurobiology of learning and memory. Science, 233, 941-947.

Thompson, R. F., Donegan, N. H., ClaRk, G. A., Lavond, D. G., LiNCOLN, J. S., MadDEN, J., MaMounas, L. A., MauK, M. D., \& MCCorMICK, D. S. (1986). Neuronal substrates of discrete, defensive conditioned reflexes, conditioned fear states, and their interactions in the rabbit. In I. Gormezano, W. K. Prokasy, \& R. F. Thompson (Eds.), Classical conditioning III (pp. 371-399). Hillsdale, NJ: Erlbaum.

VEGAS, R. (1995). Appetitive classical conditioning of the swallowing response in the pigeon (Columbia livia): Effects of the CS-US and $C S-U R$ relations. Unpublished doctoral dissertation, University of Massachusetts, Amherst.
VANDERCAR, D. H., \& SCHNEIDERMAN, N. (1967). Interstimulus interval functions in different response systems during classical discrimination conditioning of rabbits. Psychonomic Science, 9, 9-10.

WAGNER, A. R. (1969). Incidental stimuli and discrimination learning. In R. M. Gilbert \& N. S. Sutherland (Eds.), Animal discrimination learning (pp. 83-111). London: Academic Press.

WAGNER, A. R. (1976). Priming in STM: An information-processing mechanism for self-generated or retrieval-generated depression in performance. In T. J. Tighe \& R. N. Leaton (Eds.), Habituation: Perspectives from child development, animal behavior, and neurophysiology (pp. 95-128). Hillsdale, NJ: Erlbaum.

WAGNER, A. R. (1981). SOP: A model of automatic memory processing in animal behavior. In N. E. Spear \& R. R. Miller (Eds.), Information processing in animals: Memory mechanisms (pp. 5-47). Hillsdale, NJ: Erlbaum.

WAGNER, A. R., \& BRANDON, S. E. (1989). Evolution of a structured connectionist model of Pavlovian conditioning (AESOP). In S. B. Klein \& R. R. Mowrer (Eds.), Contemporary learning theories: Pavlovian conditioning and the status of traditional learning theory (pp. 149-189). Hillsdale, NJ: Erlbaum.

WaGner, A. R., \& Donegan, N. H. (1989). Some relationships between a computational model (SOP) and a neural circuit for Pavlovian (rabbit eyeblink) conditioning. In R. D. Hawkins \& G. H. Bower (Eds.), The psychology of learning and motivation: Vol. 22. Computational models of learning in simple neural systems (pp. 157-203). San Diego: Academic Press.

WAGNER, A. R., \& TERRY, W. S. (1975). Backward conditioning to a CS following an expected vs. a surprising UCS. Animal Learning \& Behavior, 3, 370-374

WEINBERGER, N. M. (1982). Effects of conditioned arousal on the auditory system. In A. L. Beckman (Ed.), The neural basis of behavior (pp. 63-91). New York: Spectrum.

Weisz, D. J., Harden, D. G., \& XiANG, Z. (1992). Effects of amygdala lesions on reflex facilitation and conditioned response acquisition during nictitating membrane response conditioning in rabbit. $B e-$ havioral Neuroscience, 106, 262-273.

Williams, D. A., Dyck, D. G., \& TAIT, R. W. (1986). Excitatory backward conditioning in conditioned punishment and conditioned suppression in rats. American Journal of Psychology, 99, 367-384.

Williams, D. A., \& OVERMIER, J. B. (1988). Backward inhibitory conditioning with signaled and unsignaled unconditioned stimuli: Distribution of trials across days and intertrial interval. Journal of Ex perimental Psychology: Animal Behavior Processes, 14, 26-35.

Williams, D. A., Travis, G. M., \& Overmier, J. B. (1986). Withincompound associations modulate the relative effectiveness of differential and Pavlovian conditioned inhibition procedures. Journal of Experimental Psychology: Animal Behavior Processes, 12, 351-362.

\section{NOTES}

1. The side-to-side head-shake response to a continuous stream of air is quite distinguishable from the up-and-down head-movement component of the startle response to a brief pulse of air (Falls \& Wagner, 1991). Testing the former simply allowed the experimenter to be confident of a clear air path directed to a sensitive surface.

2. We are unsure how to characterize the temporal relationships in a notable, related report by Vegas (1995). He observed that extending a visual CS by 150 or $1,050 \mathrm{msec}$ beyond the time that water was infused into the oral cavity, as the US, increased conditioned throat movements in the pigeon. However, he also documented that the swallowing UR that was measured did not begin until approximately 350 msec after the US was delivered and continued for several seconds thereafter. Vegas (1995) and Donahoe (personal communication, May 1994) emphasized that the extended CS preceded a portion of the UR. One may also speculate that it preceded cessation of that esophageal stimulation that was the proximal effective US.

(Manuscript received December 20, 1995; revision accepted for publication May 8, 1996.) 